\title{
TECNOLOGIA ASSISTIVA, DIREITOS HUMANOS E EDUCAÇÃO INCLUSIVA: UMA NOVA SENSIBILIDADE
}

\author{
Elaine Conte \\ Universidade La Salle (UNILASALLE), Canoas - RS, Brasil \\ Maiane Liana Hatschbach Ourique** \\ Universidade Federal do Pampa (UNIPAMPA), Bagé - RS, Brasil \\ Antonio Carlos Basegio ${ }^{* *}$ \\ Universidade La Salle (UNILASALLE), Canoas - RS, Brasil
}

RESUMO: Este ensaio aborda os percursos inclusivos da Tecnologia Assistiva (TA) e suas contribuições para a educação em direitos humanos, que, por variados caminhos, articula lutas sociais, políticas e ações pedagógicas. Traz à cena um diálogo hermenêutico, que parte da interrogação acerca de quais desafios pedagógicos a tecnologia assistiva pode trazer para o convívio com as diferenças, tendo em vista as formas cotidianas de opressão e exclusão presentes em nossa sociedade tecnológica. Além disso, tem o objetivo de discutir sobre o dispositivo pedagógico da tecnologia assistiva no processo de reconhecimento mútuo, de interação social e de construção da aprendizagem, para promover a igualdade de direitos e o exercício da cidadania. Ao final do texto, as nossas considerações sublinham que precisamos recuperar o sentido das tecnologias para a humanidade, pois somente uma nova sensibilidade que valorize a multiplicidade de experiências pode acolher as reconfigurações reflexivas de reconhecimento das diferenças.

Palavras-chave: Tecnologia assistiva. Educação inclusiva. Direitos humanos.

\footnotetext{
"Doutora em Educação pela Universidade Federal do Rio Grande do Sul (UFRGS); Professora pesquisadora do Programa de Pós-Graduação em Educação da Universidade La Salle (UNILASALLE, Canoas); Líder do Núcleo de Estudos sobre Tecnologias na Educação - NETE/CNPq. E-mail: < elaine.conte@unilasalle.edu.br > .

"Doutora em Educação pela Universidade Federal de Santa Maria (UFSM); Professora Adjunta da Universidade Federal do Pampa (UNIPAMPA). Membro do Grupo de Pesquisa Formação Cultural, Hermenêutica e Educação (GPFORMA/UFSM) e Participante do Núcleo de Estudos sobre Tecnologias na Educação (NETE/CNPq). E-mail: <maianeho@yahoo.com.br >.

" "Mestre em Educação pelo Centro Universitário La Salle (UNILASALLE, Canoas); Pós-Graduado em Pedagogia do Corpo e da Saúde pela Universidade Federal do Rio Grande do Sul (UFRGS). Participante do Núcleo de Estudos sobre Tecnologias na Educação (NETE/CNPq). E-mail: < caiobasegio@gmail.com>.
} 


\section{ASSISTIVE TECHNOLOGY, HUMAN RIGHTS AND INCLUSIVE EDUCATION: A NEW SENSITIVITY}

ABSTRACT: This essay focuses the inclusive pathways of Assistive Technology (AT) and their contribution to human rights education that, in various ways, articulates social struggles, political and pedagogical actions. It brings to the scene a hermeneutical dialogue that parts from the question about which pedagogical challenges the assistive technology can bring to the conviviality with the differences, considering the everyday forms of oppression and exclusion present in our technological society. Moreover, it aims to discuss the pedagogical tool of assistive technology in the process of mutual recognition, social interaction and construction of learning, to promote equal rights and citizenship. At the end of the text, we emphasize the need to recover the sense of technology for humanity, because only a new sensibility that values the multiplicity of experiences can accept the reflexive reconfigurations of recognition of differences.

Keywords: Assistive technology. Inclusive education. Human rights.

\section{CONSIDERAÇÕES INTRODUTÓRIAS}

Do ponto de vista da práxis formativa, a chave da compreensão sobre as tecnologias na educação é considerá-las como produção social dinâmica, pois têm condições para incorporar as experiências com as diferenças como geradoras de novas percepções e significados à sobrevivência e à existência humana. Daí podermos afirmar que a questão da deficiência ${ }^{1}$ não diz respeito apenas aos sujeitos com limitações físicas, cognitivas, emocionais ou com impotências em lidar com as múltiplas linguagens, mas abrange as dificuldades de acesso à educação, ao convívio social e ao trabalho. Kassar (2011) analisa a política de educação especial no Brasil e evidencia que as grandes barreiras na aprendizagem não existem porque as pessoas possuem deficiência, mas decorrem das expectativas sociais em relação às suas potencialidades e das relações estabelecidas entre os sujeitos e deles com os recursos tecnológicos para atender às suas necessidades. Assim, na falta de uma política que garanta a utilização dos recursos para dar conta dessas necessidades corporais ou intelectuais, alguns sujeitos tornam-se inaptos para o agir democrático, ressaltando-se cada vez mais os mecanismos sociais de discriminação e exclusão. Outra importante reflexão sobre esse ponto gira em torno de que "[...] fala-se mais e mais de inclusão, sem pensar que não se trata de incluir, trata-se sim de conhecer as diversas possibilidades para o desenvolvimento humano e de estar aberta a elas numa relação dialógica genuína” (PRESTES, 2010, p. 191). 
Nesse sentido, o objetivo deste ensaio é discutir sobre o suporte pedagógico da tecnologia assistiva $\left(\mathrm{TA}^{2}\right)$ no processo de construção da aprendizagem, de interação social e do reconhecimento mútuo, promovendo a igualdade de direitos e o exercício da cidadania. De acordo com Goffredo (1999, p. 67):

Inclusão, numa sociedade de excluídos, passa a ser palavra-chave para se alcançar a verdadeira democracia. A cidadania se estabelece pela igualdade dos direitos e deveres, e pela oportunidade de poder exercê-los plenamente. [...] embora esse movimento seja muito mais amplo, norteando, também, todas as ações que emanam dos direitos sociais, políticos e civis.

A invisibilidade das diferenças nos processos de aprendizagem é gerada, muitas vezes, pelo esquecimento das dimensões éticas e estéticas da formação e pela hipertrofia do seu caráter instrumental, que desencadeia a mitificação sobre os conhecimentos úteis e a inércia nuclear das tecnologias sobre os sujeitos produtivos de uma sociedade. Analisando de forma crítica, o uso da $\mathrm{TA}^{3}$ pode tanto servir para o recrudescimento do poder, das desigualdades e da marginalização social, quanto para o reforço de práticas inclusivas, solidárias, diversificadas e de participação social, considerando a diferença enquanto expressão da vida e singularidade humana. Nessa perspectiva, as tecnologias podem ampliar as possibilidades de autonomia e interação, potencializando a participação ativa como direito fundamental do ser humano. Se a tecnologia nada mais é do que uma dimensão da atividade humana, contraditoriamente,

Os homens inclinam-se a considerar a técnica como algo em si, um fim em si mesmo, uma força própria, esquecendo-se que ela é extensão do braço dos homens. Os meios - e a técnica é um conceito de meios dirigidos à autoconservação da espécie humana - são fetichizados, porque os fins - uma vida humana digna - encontram-se encobertos e desconectados da consciência das pessoas. (ADORNO, 1995, p. 132-133)

A fetichização da tecnologia, que visa ao controle total do homem sobre a natureza, é uma postura determinante, que pode ser combatida para o estabelecimento de mediações. Entendemos que a tecnologia pode promover a aproximação e a interação entre as pessoas, mas também sabemos que o uso desmedido distancia o sujeito do convívio com os outros, perturbando as noções sociais de realidade e tempo, a expressão das emoções, o exercício da afetividade, da tolerância, do respeito mútuo. Foi justamente essa fetichização da tecnologia, somada à destituição da condição política do humano, que levou os europeus a apoiar a causa nazista, projetando e construindo um sistema ferroviário 
que conduziria com maior rapidez 11 milhões de pessoas à morte nos campos de concentração, como lembra Adorno (1995).

Há uma tendência em distanciar, subjugar e polarizar nossas diferenças (técnico-científicas, econômicas, estéticas, morais e políticas), transformando o outro em inimigo. A própria existência humana fica submetida à invisibilidade, à animosidade, à dominação, ao isolamento e à exclusão social. Por essa razão, se pensarmos que nos constituímos como humanos (num canteiro de obras) no movimento de indeterminação e inacabamento do processo de formação intelectual, então podemos reconhecer que a própria adaptação à TA vai além de uma representação maquínica. Essa adaptação pode produzir silêncios e ausências, capazes de gerar um sentimento de exclusão, instituído e naturalizado em forma de estigmas sociais. Para Goffman(1975), o papel dos estigmas enquanto marcas sociais pode ser registrado em corpos ${ }^{4}$ e pressupostos subjetivos, na medida em que acabam transformando as relações entre os sujeitos, pois são práticas vividas no cotidiano através dos elementos da discriminação cultural institucionalizada. Ou seja, a construção do corpo faz parte da estruturação do próprio papel social, interpondo e legitimando a criação de barreiras sociais entre as pessoas e a sociedade, assim como os ambientes para a reabilitação humana e a educação inclusiva pela via da TA.

Nesse sentido, propomos explorar e problematizar as contribuições da tecnologia assistiva que se legitimam no campo da educação, centrando na seguinte questão: quais desafios pedagógicos a TA pode trazer para o convívio com as diferenças, tendo em vista as formas cotidianas de opressão e exclusão presentes em uma sociedade tecnológica? Ainda, em tempos de emergência da inclusão, quais as repercussões que o uso da TA tem promovido para o reconhecimento do outro e a participação ativa na sociedade? Para problematizar as barreiras sociais à inclusão, enfocamos as condições de um novo tipo de racionalidade tecnológica e social para a aprendizagem na diversidade, sem violar a integridade do sujeito em suas diferenças ou suprimi-lo. Levantamos aqui a hipótese de que é possível aprender cooperativamente e construir distintos percursos de conhecimentos em projetos inclusivos mediados pela TA, para atender às necessidades de interação e reconhecimento das diferenças que emergem nas sociedades complexas.

$\mathrm{Na}$ atualidade, a hipercomputação, a biotecnologia e a neurociência implicam outras redefinições do humano, das formas de produzir e vivenciar a cultura, da criação e relação com os artifícios existentes, que geram hiperatividade e, ao mesmo tempo, ampliação 
das habilidades da natureza humana. Desde o período do pós-guerra, a sociedade ocidental tem se esforçado para reconstruir as bases do direito internacional e dos direitos humanos, orientados, especialmente, por referenciais éticos pós-metafísicos, ou seja, considerando o humano como ser histórico e cultural, que cria e transforma seu espaço ao mesmo tempo que modifica a si mesmo. Ponderando acerca da igualdade como uma construção humana, inscrita no princípio da justiça, Arendt (2012, p. 410) afirma: "Não nascemos iguais; tornamonos iguais como membros de um grupo por força da nossa decisão de nos garantirmos direitos reciprocamente iguais".

A TA tem sua origem justamente nas tentativas de recuperar um mínimo de dignidade a quem sofria os reveses da tirania nazista, em uma época em que o crescimento das forças produtivas foi proporcional ao das forças destrutivas, pois quem controlava a tecnologia ("os senhores do mundo", diria Adorno) estava a serviço do extermínio das diferenças, da homogeneização e da barbárie. Frente à regressão da ação humana ao seu poder de autodestruição (a Primeira Guerra foi marcada por armadilhas reducionistas biopsicossociais) e de manutenção das desigualdades políticas e sociais, já que mostra os aspectos sombrios, dominadores, manipuladores e ideológicos implicados no conhecimento e na prática técnico-científica. A TA surge como um esforço social e cultural para buscar transformações abrangendo recursos e relacionamentos físicos, humanos, sociais e digitais, com vistas ao diálogo e à integração em comunidades, instituições e sociedades. Se o valor de uma tecnologia não reside na abstração (mecanização) ou no afastamento dos problemas sociais concretos, seu sentido vincula-se diretamente à linguagem e às relações que estabelecemos no campo da práxis vital.

No passado recente, em um canal de notícias ${ }^{5}$ on-line, foi informado pelo secretário de Ciência e Tecnologia para Inclusão Social, Eron Bezerra, que os financiamentos da área "[...] promoveram a criação de aproximadamente 1,5 mil produtos voltados para dar mais independência e qualidade de vida a pessoas com deficiência”. As investigações sobre TA são desenvolvidas no Brasil em cerca de 70 grupos de pesquisa, que contribuem para ampliar e criar estímulos compensadores e alternativos à integração e à inclusão social dos sujeitos excluídos dos contextos escolares, através de recursos simples e equipamentos tecnológicos. Com isso, também a configuração do processo educativo - especialmente, o formal - ganha novos contornos. Observamos, no discurso educacional inclusivo, questões que vêm somar-se à educação em direitos humanos, tendo um sentido vivo, 
presente, algo que é próprio do exercício de respeito e valorização do outro, não mais se restringindo à mera função de conscientização sobre os direitos assegurados pelo Estado, a serem reivindicados no futuro.

A partir desse núcleo de debates, identificamos, na abordagem do reconhecimento, um amplo potencial para reconstruir as práticas educativas e sociais relacionadas às pessoas em situação de exclusão social. A primeira parte do trabalho lança um olhar compreensivo sobre os aspectos históricos no campo de forças da TA, referindo-se a questões de justificação normativa e validade inclusiva. A segunda parte busca reconstruir os conflitos, as ambiguidades e as tensões da TA na práxis educativa, abordando as novas reivindicações tecnológicas de um mundo que banaliza as relações culturais e as interações sociais. Gradativamente, sustentamos na experiência do reconhecimento do outro uma possibilidade de revisão dos conflitos mencionados, evidenciando desdobramentos à reflexão crítica acerca da sujeição tecnológica presente. A luta por reconhecimento das diferenças, das múltiplas vozes e necessidades das pessoas passa pelo trabalho de reelaboração da tecnologia assistiva na educação, a partir dos contextos inclusivos e de sensibilidade às diferenças, como forma de participação que intensifica o aprender recíproco, solidário e plural, assegurando a dignidade humana na possibilidade de expressão e relação de estima ao outro.

\section{ASPECTOS HISTÓRICOS DA TECNOLOGIA ASSISTIVA (TA)}

Sabemos que a segregação social, as desigualdades, as vulnerabilidades e a marginalização preconceituosa dos sujeitos com deficiências têm raízes históricas profundas, que envolvem a discussão sobre o reconhecimento de sua condição humana, política, de participação ativa, de respeito às necessidades de liberdade, interação e expressão. Sem dúvida, os aspectos históricos da TA revelam uma experiência de luta social por reconhecimento como um processo de desdobramento ontológico (de uma totalidade que se reconstrói a partir da diferença), que integra um papel constitutivo da humanidade atravessado por metas de autoconservação ou por chances de sobrevivência com força solidarizante. A TA originalmente brota de necessidades puramente militares, no sentido de reabilitar pessoas que foram vítimas de ações banais da Segunda Grande Guerra ${ }^{6}$, em função de atrofias, danos corporais, surdez, dificuldades intelectuais e de desenvolvimento, causadoras de exclusão social. Se, por um lado, 
a inclusão da TA é marcada como uma forma de garantir direitos basilares como liberdade, dignidade, comunicação, mobilidade, acessibilidade e igualdade social (condição política e cidadã), por outro, surge como um antídoto à correção e ao saneamento de barbarismos e violências cometidas no período de guerra (técnica a serviço da morte), que contribuiu para o encobrimento e o desenvolvimento de uma política de exclusão social. Por tudo isso, a TA tem em seu gene a interdependência do binômio conflituoso inclusão e exclusão. Essas tecnologias foram concebidas em estreita relação com ações políticas, exigências ideológicas e socioeconômicas de profundas divergências, voltadas para a resolução de problemas coletivos e assistenciais, no sentido do controle sobre a população promotora da desordem. Assim, o poder tecnológico está correlacionado com o poder econômico, mais preocupado com a produção de artifícios úteis e a prestação de serviços do que com os mecanismos de democratização dessa oferta e seus efeitos sobre a formação humana.

Durante as primeiras décadas do século XX, mais uma vez a dimensão da instrumentalidade revela-se como uma forma de domínio do campo da política, pois a ideia de controle absoluto sobre a técnica retoma a promessa cartesiana de tornar o homem mestre e senhor da natureza, tendo como ideia orientadora de humanidade aquela próxima do sagrado, da metafísica. Essa noção está presente na Declaração dos Direitos do Homem e do Cidadão de 1789 (durante a Revolução Francesa), marco importante na história da humanidade. Pensadores de inspiração iluminista, entre eles Montesquieu, Voltaire e Rousseau, já apregoavam, na época, a necessidade de um documento que protegesse os direitos do homem e limitasse o poder do estado. Contudo, essa Declaração nunca foi reconhecida pelos países, pois, em uma sociedade secularizada e emancipada, entendia-se que todo povo com soberania nacional era capaz de assegurar, naturalmente, os direitos "inalienáveis" de seus cidadãos. O paradoxo dessa normatividade de direito humano mostrou-se da forma mais cruel no início do século $\mathrm{XX}$, pois esse ser humano teria seus direitos destituídos no mesmo momento em que deixasse de ter um governo para protegê-lo ${ }^{7}$.

Os próprios nazistas começaram a sua exterminação dos judeus privando-os, primeiro, de toda condição legal (isto é, da condição de cidadãos de segunda classe) e separando-os do mundo para ajuntá-los em guetos e campos de concentração; e, antes de acionarem as câmaras de gás, haviam apalpado cuidadosamente o terreno e verificado, para sua satisfação, que nenhum país reclamava aquela gente. O importante é que se criou uma condição de completa privação de direitos antes que o direito à vida fosse ameaçado. (ARENDT, 2012, p. 402) 
Dessa situação totalitária, que levou milhares de pessoas à condição de apátridas, refugiadas ou vítimas nos campos de extermínio, Arendt (2012, p. 403) assegura que a violação mais grave dos direitos humanos é a "privação de um lugar no mundo que torne a opinião significativa e a ação eficaz". Nessa perspectiva, entre tantos outros dispositivos e posturas, insere-se a importância de dispor a TA a quem necessita restituir, em alguma medida, sua integridade humana, ampliando suas possibilidades de interação, entendimento, expressão e apoio social.

Conforme adverte Heidegger (2001), não deveríamos tentar dominar a técnica, mas compreendê-la e apreendê-la na construção do pensar, como forma de se envolver em práticas sociais significativas que atribuem sentido à própria vida. Nesse contexto, percebemos que o caminho de construção do conhecimento pedagógico passa necessariamente pela linguagem de acesso ao outro e ao mundo, "[...] capaz de abrir nossa Presença à essência da técnica”, enquanto reflexão e acolhimento do outro que aprende na pluralidade de linguagens (HEIDEGGER, 2001, p. 11). Afinal, a experiência dos limites de tudo que é técnico passa pelo encobrimento de sua dimensão instrumental e antropológica, ambas recíprocas e inseparáveis da ação humana, influenciada tanto pela transfiguração da experiência no mundo, quanto pela visão alienante do consumo e da uniformidade cultural (HEIDEGGER, 2001). Sem dúvida, existem aspectos positivos das tecnologias que provocam a autorreflexão na educação. No entanto, o empobrecimento de relações interpessoais e do pensar autônomo revela as consequências do progresso tecnológico que negligencia e torna sem sentido a interação comunicativa no processo pedagógico, reificando as diferenças entre as pessoas. A partir dessas ponderações, compreendemos a importância de que o progresso tecnológico e as transformações materiais na educação sejam orientados por uma formação inclusiva e promotora de humanização, em seu sentido ético mais caro.

Dito isso, talvez o grande problema da incapacidade de pensar os aportes técnicos na educação esteja na substituição das reais necessidades de democratização de acesso que a TA pode impulsionar, como forma de explorar as motivações e as disposições humanizadoras. A TA é essencial para a vida porque facilita o pleno desenvolvimento humano (pelas relações e o envolvimento social), divergindo da lógica de ser apenas uma determinação oficial e hegemônica para um conjunto de acidentes - acobertada por dispositivos jurídicos, sociológicos e de exclusão (CHAUÍ, 1999). Os dispositivos de exclusão contra a vida advêm de uma obsessão instrumental (fábrica de perversidades totalizantes, automatizadas na unificação 
e na simplificação da produção de desigualdades, autoritarismos, corrupção, intolerâncias) ou homogeneização cultural, que regula as relações sociais como algo institucionalizado, para agirmos como máquinas, aniquilando os outros desajustados.

As origens históricas da humanidade revelam que os sofrimentos e as violências ocultas advêm dos processos de comercialização, burocratização, cientificização e institucionalização. Nas palavras de Habermas (2004, p. 68), a lógica da exclusão nega os requisitos de equidade na participação da vida coletiva, pois conserva “[...] 'chagas ocultas' que são a marginalização social e a exclusão cultural". Habermas (1996) é um crítico da razão instrumental e encontra no conceito de unidimensionalidade a base para uma crítica da tecnologia enquanto sinônimo de administração total nas sociedades avançadas e nos modos técnicos de pensar e agir que limitam as comunicações. Mas Habermas (1996) reconhece que os interesses sociais ainda determinam a direção, as funções e o ritmo do progresso técnico. Isso significa também relacionar a discussão da TA ao campo da arte e do pensar a partir de recriações dos objetos técnicos. Com base nos filmes de Charlie Chaplin (1889-1977), podemos ilustrar diferentes formas de usar as coisas e potencializar esses objetos por meio do jogo interpretativo, ultrapassando, assim, os limites de seus usos por novas leituras. Chaplin, através do gesto, alegra, denuncia, convence, reconstrói e mobiliza aprendizagens. A arte é um bom exemplo de como podemos nos valer da técnica para compreendermos criticamente o mundo.

Os atos de reconhecer e ser reconhecido são eminentemente humanos, por isso possuem caráter social, político e pedagógico, constituindo nossa condição de manifestação humana, de criação e reconstrução de conhecimentos. Ao inserirmos a compaixão, a empatia e a dignidade humana como princípios dos processos de aprendizagem, damo-nos conta de que a exclusão dos outros significa a redução da capacidade de apreender de nós mesmos. A ideia da segregação dos sujeitos pode ser analisada na instância da evasão escolar, por exemplo, uma espécie de marginalização e exclusão dos outros de forma institucionalizada, dependente da nossa própria vontade (um "eufemismo cruel”, diria Freire). Ou seja, a exclusão social e cultural apresenta-se através de muitas facetas, revelando-se no desrespeito à condição peculiar de desenvolvimento humano, submetendo e reprimindo a autenticidade, a criatividade e a autonomia do outro pelas ações que realizamos (talvez ameaçadoras, desmotivadoras e autoritárias), inclusive por meio das tecnologias. 
Seguidamente, a incapacidade humana passa por conflitos e envolve situações de extremo sofrimento, sendo necessário transformar a falta de reconhecimento em potencialidade de ação, para rearticular os sentidos da educação inclusiva em sua pluralidade e diversidade. No pensamento de Honneth (2003), nós só podemos assumir a perspectiva do outro quando o reconhecemos a partir do seu papel na socialização, na medida em que os outros constituem a mediação comunicativa para o mundo da vida. Nesse encontro de diferentes experiências, ocorrem conflitos, "porque só através da violação recíproca de suas pretensões subjetivas os indivíduos podem adquirir um saber sobre se o outro também se reconhece neles como uma "totalidade"' (HONNETH, 2003, p. 63). A evolução da humanidade ocorre na defesa de pretensões normativas socialmente ancoradas no mundo da vida e traduzidas em lutas pelo reconhecimento de identidades em movimentos sociais pautados pela alteridade.

A política governamental brasileira voltada para a TA sinaliza para o atendimento das deficiências dos sujeitos, reconhecendo seus direitos de cidadãos em receber os recursos os quais demandam. Mas esses sujeitos, excluídos socialmente, geralmente, não dispõem de informações sobre a legislação, pela inexistência de uma orientação e caminhos de acesso a esses serviços públicos. As informações existentes estão pulverizadas e ficam, muitas vezes, restritas aos diferentes agentes de governo e a poucos profissionais que atuam nas áreas da saúde, assistência social, direitos humanos, educação e trabalho. Certamente, a integração social da tecnologia envolve o acesso à informação para garantir a qualidade de vida como condição de participação social, formação humana e interação no cotidiano cultural e político.

De acordo com a definição preconizada no Brasil pelo Comitê de Ajudas Técnicas $(\mathrm{CAT})^{8}$, expedida pela Secretaria Especial dos Direitos Humanos da Presidência da República, elucida-se:

Tecnologia Assistiva é uma área do conhecimento, de característica interdisciplinar, que engloba produtos, recursos, metodologias, estratégias, práticas e serviços que objetivam promover a funcionalidade, relacionada à atividade e participação, de pessoas com deficiência, incapacidades ou mobilidade reduzida, visando sua autonomia, independência, qualidade de vida e inclusão social. (BRASIL, 2009a, p. 9)

A política de educação inclusiva suscitou o desenvolvimento de pesquisas voltadas para a criação e o desenvolvimento de recursos e métodos educacionais visando atender às especificidades de estudantes com deficiência nas escolas, projetados para superar as barreiras da comunicação, melhorar a funcionalidade e a mobilidade, favorecendo a autonomia pessoal, movimentos sensoriais e mentais, rumo à plena 
inclusão social. Para atender à diversidade educacional (alcançar níveis mais complexos e evolutivos de aprendizagem), é necessário considerar as limitações cognitivas e motoras dos estudantes, bem como compreender e reconhecer a própria condição humana, em termos de interesses, sensibilidades, motivações, complexidades (singularidades próprias), olhares e experiências, sem abandonar ou expulsar as diferenças de nosso mundo, mas oportunizando diálogos culturais de liberdade, pluralidade e espontaneidade no sentido formativo do (re)conhecimento e da reinvenção social.

O uso da TA passa por metamorfoses nas esferas cultural e pedagógica, pautadas nas novas formas de lidar com as debilidades sociais e com o conhecimento, produzido em escala geométrica. Isso conduz a uma mudança da própria natureza da instrumentalidade, reconstruída sob o ponto de vista da arte, do respeito e do direito à convivência comunitária. Nessa esteira, temos presenciado uma reconfiguração do caráter compensatório da TA - contido no início do século XX - para potencializador de vínculos sociais dos sujeitos com impedimentos de exercitar plenamente seu direito a dignidade, respeito, liberdade de expressão, educação, convívio social.

De acordo com Lévy (2001), as novas tecnologias da inteligência individual e coletiva mudam profundamente as questões postas na atualidade e os problemas da educação e da formação. O que é preciso aprender não pode mais ser dominado com antecedência, pois se situa na linguagem e no conhecimento reinventado constantemente entre os atores sociais. O caráter de fundo da tecnologia da inteligência - como potência de autocriação - reside na possibilidade de interconexão e da integração coletiva na esfera cultural enquanto um fluxo comunicativo. A propensão à tecnologia da inteligência, esta colaborativa, plural, aberta e em transformação, representa a possibilidade de compreender seus sentidos e aumentar as capacidades cognitivas das pessoas e dos grupos (através de memória, percepção, raciocínio, aprendizagem ou criação), tensionando a palavra e colocando em marcha uma reconfiguração social, cultural e política de uma pluralidade de conversação de maneira mais livre (LÉVY, 2001).

Pensar a TA como condição de possibilidade de aprendizado mútuo e reconstrutivo significa afastar-se da visão de que o desenvolvimento técnico representa apenas suplemento ao corpo e à mente humana, desmitificando o entendimento comum de que o uso do aparato técnico possui somente uma função causal e determinística. As tecnologias são dispositivos agregadores de experiência, elementos de aproximação da prática social, convivência, interação, conhecimento e comprometimento com o outro. 
A tecnologia vem desenvolvendo-se, impulsionada pela necessidade de ampliar e aguçar a sensibilidade humana. Isto é, a tecnologia alarga as capacidades da percepção humana: por exemplo, ver mais longe, de forma mais fina, mais concentrada, ultrapassando limites, obstáculos e barreiras como falta de iluminação (telescópios, microscópios, raios-X, aparelhos de luz infravermelha, microcâmeras). Escutar melhor com ajuda das tecnologias, tais como radares, sonares, ultrassom. Sentir melhor através de sensores, da ressonância magnética etc. Outras tecnologias ajudam na memória e na organização de dados e de informações, como o moderno computador. Mas todas essas tecnologias não têm sentido se por trás delas não está uma sensibilidade atenta [...]. (SÁNCHEZ GAMBOA, 2013, p. 57-58)

Hoje, não vivemos conforme nossas próprias determinações, mas de acordo com as associações heterônomas, da organização social e do planejamento da realidade intersubjetiva, que sobrevive na tensão entre interesses e campos de força opostos. As tecnologias trazem um potencial humano e social (de inclusão, tecnologia social e reconhecimento) que também abriga fatores desagregadores, aniquiladores do pensar (câmaras de gás dos campos de extermínio, ambientes de competição desumana na lógica da produção, atmosfera hostil e opressiva da sala de aula). Esses espaços, certamente, instigam inquietações e conflitos para a construção de relações sociais justas e solidárias. Apontam, ainda, para a ambiguidade das tecnologias, que seriam simultaneamente adequação, emancipação, libertação e marginalização sociocultural. O tratamento das tecnologias como neutras, formais e puramente instrumentais acaba relativizando e obscurecendo suas dimensões comunicativas, seus limites e deficiências.

A luta por reconhecimento ${ }^{9}$ aqui proposta é interpretada como princípio educativo de qualquer dinâmica social inclusiva, que culmina com o processo de formação da identidade e a expressão linguística do outro, na utilização de instrumentos ao agir voltado à interação, ao entendimento, à reciprocidade, à satisfação de carências e necessidades humanas e à libertação da degradação humana no mundo. Honneth (2003) destaca que, nas aprendizagens cooperativas e sociais, as diferenças constituem-se em oportunidade de enriquecimento e reconhecimento mútuo. Com base nesse projeto, Werle (2004, p. 52) acrescenta a ideia de:

[...] desdobrar um conceito de intersubjetividade, onde formas diferentes de sociabilidade vão surgindo no decorrer dos próprios conflitos em torno do reconhecimento, nas quais as pessoas ao mesmo tempo afirmam sua subjetividade autônoma e reconhecem-se na sua pertença comunitária. Ou seja, a relação constitutiva entre identidade pessoal e a práxis cultural e as instituições é entendida não como relação instrumental ou relação de dependência orgânica, substantiva, do indivíduo com a comunidade, mas como relação reflexiva de reconhecimento recíproco. O reconhecimento permite uma reconciliação sempre passível de revisão, quando for o caso, entre diferença e identidade. 
Ao abordar o assunto da TA na educação, Bersch (2008, p. 2) defende que a tecnologia assistiva precisa ser entendida como " $[. .$. um auxílio que promoverá a ampliação de uma habilidade funcional ou deficitária, ou ainda, que possibilitará a realização de uma função desejada e que se encontra impedida", devido a uma limitação em termos fisiológicos e psicológicos, inatos ou adquiridos pelos sujeitos. $\mathrm{O}$ acesso à TA na escola permite aos participantes até então destoantes dos padrões normais e àqueles atingidos por estigmas sociais a possibilidade de assumir um papel mais ativo na própria dinâmica de aprendizagem e no processo conjunto de interações sociais. A TA na educação vai além do mero auxílio ao estudante para realizar as tarefas escolares, abrindo possibilidades para novas perspectivas formativas do processo de desenvolvimento humano, para que o sujeito possa atuar de forma solidária, sensível, construtiva e dialética com o outro e com o mundo alicerçado na metamorfose do aprender. Recentemente, verifica-se uma grande diversidade de recursos tecnológicos para assegurar condições de acesso e reabilitação de pessoas com limitações em termos de incapacidades sensoriais, motoras, cognitivas e de aprendizagem, de linguagem e oralidade, de mobilidade e autonomia, do relacionamento interpessoal e da participação social, abrindo para outras sensibilidades e para a melhor expressão e contextualização dos problemas educativos e de uma cidadania crítica.

De modo geral, os dispositivos de inclusão lidam com as diferenças e o respeito às diversidades dos sujeitos, que não se faz na invisibilidade ou na ausência de diálogo em relação às resistências, mas reconhecendo o outro como um ser diferente e politicamente legítimo, cuja relação baseia-se no respeito mútuo, na confiança solidária e na colaboração. A TA apresenta um potencial humanista de valor social diante dos eventuais desajustes no ritmo de aprendizado (como um processo que é plural, complexo e múltiplo de sentido), uma vez que pode auxiliar e criar estímulos à capacidade de percepção, linguagem e compreensão ontológica, pois articula diferentes formas de estar juntos e uma multiplicidade de saberes. Trata-se de reivindicar o direito de reconhecimento social na experiência com a TA socialmente validada, que repercute em todas as dimensões da vida, como um meio pelo qual as pessoas compartilham suas experiências e aprendem com o outro, ou seja, é um exercício de cidadania e de vivência cultural. O conhecimento integrado da TA abrangendo recursos e relacionamentos físicos, humanos e sociais complementares aos processos cognitivos de aprendizagens abre para outras sensibilidades sobre a presença e o reconhecimento do outro em sua humanidade, combinando com uma formação recíproca e plural que resulta em transformação do pensamento e passa pela dinâmica da linguagem. 
Frequentemente, percebemos que as crianças e os jovens são receptivos às variadas tecnologias (eles aprendem sobre elas). No entanto, isso não repercute diretamente no desenvolvimento cognitivo, social e afetivo em termos de relação interpessoal, de lógica compreensiva de textos e no aprendizado de problemas matemáticos, desfavorecendo, muitas vezes, os usos, os sentidos e a ressignificação das palavras. Diversamente, as tecnologias poderiam funcionar como elementos instigadores aos processos educativos e à pluralidade formativa estimulada pelo acesso à internet, para reunir diferentes papéis e jogos com um sentido ético e emancipatório. A questão da inclusão da pessoa com deficiência na escola por meio da TA é algo complexo, mas que torna possível e viável a integração e a cidadania de todos. Esse trabalho vai além da adaptação aos recursos técnicos e à inclinação tecnológica, uma vez que precisa apoiar e relacionar as necessidades singulares a uma "tecnologia da inteligência" (LÉVY, 2001), que combina elementos de "luta por reconhecimento" (HONNETH, 2003).

Para Honneth (2003), a lógica do reconhecimento não culmina com a experiência da autonomia pessoal, experimentada na relação com outro a partir da unilateralidade da relação de reconhecimento. Segundo ele, a luta por reconhecimento exige a reciprocidade radical do relacionamento social ancorado na liberdade de agir do outro, que conduz ao autorreconhecimento e à condição de possibilidade de uma vida digna, solidária e justa. Dessa maneira, aposta no desenvolvimento de relações sociais com base em uma sociedade pluralista, aberta às diferentes opções de vida ou às orientações dos conflitos emergentes, para ampliar a chance de buscar autonomia, autoestima e solidariedade como princípios da construção social.

A estrutura complexa oriunda dessas transformações não poderia forçar uma nova homogeneização social niveladora das diferenças (dimensão unidimensional), mas aceitá-las, transformandoas em fontes de legitimidade à heterogeneidade cultural. Podemos destacar que, até hoje, a sociedade vem concentrando suas políticas sociais na (re)inclusão das pessoas no sistema educacional para possibilitar uma vida autônoma e a sociabilidade. Na sociedade contemporânea, toda pessoa tem o direito à educação para a construção de relações sociais justas e solidárias, mas, paradoxalmente, essa educação inclusiva parece não ter como satisfazer às demandas por autonomia, autoestima, reconhecimento das diferenças e dos contextos envolvidos na dinâmica da práxis pedagógica, pois não garante as condições de acesso e materiais para sua realização e desenvolvimento sociocultural. Os projetos de inclusão, em termos de reconhecimento das diferenças e da diversidade de vida, poderiam dar 
vOz àqueles sujeitos que fogem à normalidade niveladora, tendo, assim, a sua autonomia respeitada. O reconhecimento leva em consideração a pessoa em suas dimensões subjetiva, objetiva e social, de modo que tudo vem influenciando sua socialização no campo educativo como espaço para a construção de experiências formativas e sociais.

Ressignificando a teoria de Honneth (2003) como uma ação projetada à educação inclusiva, podemos dizer que o respeito às pessoas com deficiência passa pelo reconhecimento do outro por meio de três relações. A primeira está na percepção do outro pelos laços de amor e afeto no cotidiano escolar, pois, através dos efeitos da presença do outro, nós nos diferenciamos e singularizamos, o que significa olhar a sala de aula como espaço de desenvolvimento de autoestima, autoconfiança, personalidade e resistência à discriminação e à marginalização do que é estranho. A segunda categoria é a do direito à igualdade por meio de políticas que criam uma cultura de respeito, dignidade, participação e acesso a recursos de forma igualitária para todos. A ação de reconhecimento mútuo pelas políticas de educação inclusiva é também geradora de autorrespeito com a legislação, incluindo os professores, que são os mobilizadores do diálogo com as políticas por meio de suas práticas. A terceira relação é a da solidariedade, que passa pela contribuição de cada sujeito no compartilhamento de valores éticos e relações comunitárias, produzindo autorrealização. Tais estudos indicam que a construção cooperativa do saber cultural que produz singularidades de leitura de mundo e oportunidades diversas de conhecer tem na estima e no acolhimento do outro o principal dispositivo de mudança social, capaz de produzir intersubjetividades emancipadas, pois os sujeitos conseguem superar as limitações do processo biológico da vida.

\section{AS TECNOLOGIAS NA EDUCAÇÃO E O RECONHECIMENTO DA EDUCAÇÃO INCLUSIVA}

Debater sobre a inclusão significa abordar as noções políticas, os interesses sociais, os recursos técnicos e as práticas pedagógicas, no sentido de sensibilizar os conhecimentos no encontro com o outro e afirmar o diálogo com a formação de professores para nortear a força de trabalho inclusivo na escola. As questões profissionais e econômicas estão atreladas à produção da deficiência na atualidade e aos projetos pedagógicos que giram em torno das questões técnicas de ensino, da definição dos conteúdos curriculares a serem ensinados e da organização institucional do ensino. A preocupação e o planejamento com respeito à formação e à capacitação humana para trabalhar com as deficiências com foco nas práticas e nas experiências de inclusão, pela via da TA, 
iniciam nas diretrizes do Ministério da Educação somente por volta de 2000 (MASINI, 2011). Há ainda uma carência de conhecimentos pragmáticos na formação inicial e continuada, sobretudo no que se refere ao papel desempenhado pelos professores no trabalho com as deficiências múltiplas (PLETSCH, 2015). Na atuação profissional, o professor percebe uma incompatibilidade entre os conteúdos normatizados e aperfeiçoados na academia e as necessidades concretas dos sujeitos, tendo muitas vezes que reformular planejamentos em conflito com suas convicções pessoais (formação) ou com as diretrizes institucionais de ensino (ambiente social). Na verdade, a diversidade da formação subjetiva e social aponta um alto potencial de conflito, diferentemente da racionalidade técnica e burocrática do sistema legal, que exige a uniformização e o nivelamento das condições de ensino e aprendizagem, por meio de regras e modelos. Tal prerrogativa niveladora reforça as diretrizes profissionais que delimitam o alcance e o limite da responsabilidade dos professores (em rotinas engessadas do processo educativo), mas, ao mesmo tempo, reprime os impulsos da atuação norteada pela autonomia e a autoestima. Os processos de educação e de formação precisam ser interpretados como um campo aberto de experiências sociais, orientados para o fortalecimento de relações educativas e sociais justas e solidárias.

A profissionalização de educadores no trabalho com a educação inclusiva no Brasil traz a necessidade de estabelecer um sistema educacional abrangente e de referência aos processos culturais de socialização, uma vez que os sujeitos se formam e consolidam suas aprendizagens e decisões a partir de orientações construídas em rede social e nos modos de atuação ao longo da vida. A defasagem formativa com o uso das tecnologias, por exemplo, determina a diferença entre a marginalização dos recursos tomados de forma isolada e a inclusão do letramento digital em "práticas sociais significativas" (WARSCHAUER, 2006, p. 64). Daí que a integração social das tecnologias na educação nos incita a rever e buscar meios para incorporar novos sentidos à TA, para além da identificação com a neutralidade e a instrumentalidade, pois são elementos fundamentais e complementares da prática social. Mas, como bem argumenta Warschauer (2006, p. 289), para promover a inclusão social em termos de reconhecimento intersubjetivo e relações humanas, "as tarefas são imensas, assim como o desafio: reduzir a marginalização, a pobreza e a desigualdade, e estender a inclusão social e econômica para todos".

O processo formativo e educativo carece de uma recuperação do sentido eminentemente social da relação pedagógica, uma vez que é preciso reconhecer o estudante com deficiência como alguém 
capaz de aprender e obter novos conhecimentos com os outros atores envolvidos, a partir de técnicas de mediação de conflitos ou utilizando experiências com práticas dialógicas e relacionais. Nesse sentido, a teoria de reconhecimento pode contribuir para pensar a educação, justamente porque expressa a necessidade do enfrentamento dos desafios do pluralismo social e cultural, segundo o laço social tornado emocional de uma aprendizagem intersubjetiva. $\mathrm{O}$ reconhecimento do sujeito enquanto princípio da inclusão pode ser compreendido na prática escolar como um processo constante de autorreflexão e transformação. "A prática da inclusão implica no reconhecimento das diferenças dos alunos e na concepção de que a aprendizagem é construída em cooperação a partir das solicitações do meio, tendo o sujeito de conhecimento como um sujeito autonômo" (FIGUEIREDO, 2010, p. 66).

A falta de vínculos com as necessidades cotidianas dos sujeitos pela suposta racionalidade técnico-burocrática e objetiva do conhecimento pode inibir a concreta experiência de reconhecimento social mútuo, como conquista da autonomia e da autoestima, que é a base da interação educativa mutável e da própria racionalidade. Considerando-se os aspectos exclusivamente técnicos, "a utopia da comunicação" poderia ser um caminho possível para fomentar espaços democráticos e promover a acessibilidade de informações, mas envolve também o questionamento das implicações e das fragilidades dos projetos técnicos nas interações sociais, que podem ser controladas, padronizadas e massificadas, perdendo de vista o respeito às necessidades dos sujeitos (BRETON, 1994).

Existe uma carência de pesquisas acerca dos problemas presentes nas ações pedagógicas por meio da TA, que vão desde as dificuldades de infraestrutura, materiais e recursos tecnológicos adequados para atender às necessidades educacionais até a incapacidade dos sujeitos de usar a linguagem oral como meio para realizar a comunicação. Segundo Nunes et al. (2011, p. 6), para auxiliar no desenvolvimento da comunicação, o uso da TA "envolve o uso de gestos manuais, expressões faciais e corporais, símbolos gráficos (bidimensionais, como fotografias, gravuras, desenhos e a linguagem alfabética, e tridimensionais, como objetos reais e miniaturas), vOz digitalizada ou sintetizada". Além disso, surgem os problemas econômicos relacionados ao transporte adaptado à escola, a falta de um trabalho integrado com os profissionais de outras áreas (os estudantes têm convulsões e apneias), assim como a ausência da participação cooperativa na elaboração do trabalho entre o professor da sala de recursos multifuncionais e o da classe regular. $\mathrm{O}$ professor necessita ter acesso aos diversos conhecimentos para compor uma formação mais ampla, atendendo e apoiando as mais diversas 
exigências dos alunos e os quefazeres pedagógicos. Aprender a usar a TA e reconhecer a complexidade e as possibilidades de o ser humano se recuperar e progredir com a apropriação tecnológica e cultural são ações imperativas nessa nova sensibilidade que a educação inclusiva exige.

Tal debate promove a abertura do campo educativo para a TA, visto que é, sem dúvida, um fator positivo às aprendizagens, pois facilita impulsos à humanização do homem e à democratização do saber, dando voz e condições para que sejam incluídas pessoas antes excluídas do intercâmbio social. No entanto, existem ambiguidades e paradoxos nesse progresso técnico, sendo que a acessibilidade dos espaços pedagógicos é acompanhada pela perda do contato com as necessidades e os desafios concretos da experiência social provocada pelo imperialismo das tecnologias importadas e desligadas das dificuldades de quem as utiliza, perdendo-se o sentido da inclusão em termos pragmáticos. $\mathrm{Na}$ verdade, as ações inclusivas precisam atender a todos na cidadania global, preparando para o convívio com a diversidade nas relações sociais, tendo em vista que é um fenômeno humano. Sobre essa questão, Perrenoud (2001) denuncia que o fracasso das relações escolares nasce da "indiferença às diferenças", proveniente tanto da natureza biológica (diferença de idade, intelectual, corporal, sensorial), quanto de uma desigualdade moral, que é estabelecida por convenções políticas e consentida na esfera pública (violações de direitos, como é o caso da homogeneização, do abandono dos prédios escolares ou da condição humilhante de professores em aceitar um salário parcelado).

\footnotetext{
No início do ano, um professor de ensino fundamental depara-se com 20 a 25 crianças diferentes em tamanho, desenvolvimento físico, fisiologia, resistência ao cansaço, capacidades de atenção e de trabalho; em capacidade perceptiva, manual e gestual; em gostos e capacidades criativas; em personalidade, caráter, atitudes, opiniões, interesses, imagens de si, identidade pessoal, confiança em si; em desenvolvimento intelectual; em modos e capacidades de relação e comunicação; em linguagem e cultura; em saberes e experiências aquisições escolares; em hábitos e modo de vida fora da escola; em experiências e aquisições escolares anteriores; em aparência física, postura, higiene corporal, vestimenta, corpulência, forma de se mover; em sexo, origem social, origem religiosa, nacional ou étnica; em sentimentos, projetos, vontades, energias do momento. (PERRENOUD, 2001, p. 69)
}

Ainda hoje, a sensibilidade ao que é diverso constitui um problema para a educação, pois persiste a tendência a adequar (enquadrar) os alunos em um determinado padrão de aprendizagem, desconsiderando as singularidades e as diferenças. As políticas públicas de inclusão implantadas no Brasil, conforme Bezerra e Souza (2012), não são suficientes, pois o acesso à escola não pressupõe formação de 
qualidade, apenas assegura a inserção do estudante. Nesse caso, o sujeito diferente, ao invés de ter reconhecido o seu direito de manifestar-se de forma distinta daquela estabelecida como padrão, passa a ser visto como incapaz (limitado) de acompanhar o processo de aprendizagem, tornando-se, muitas vezes, vítima de exclusão e preconceitos dos outros. Cabe destacar que a perspectiva aqui apresentada sobre as tecnologias para o trabalho com as crianças deficientes está em sincronia com as Diretrizes Operacionais do AEE, que definem como uma das atribuições do professor do AEE "VII - ensinar e usar a tecnologia assistiva de forma a ampliar habilidades funcionais dos alunos, promovendo autonomia e participação" (BRASIL, 2009b). No entanto, cabe destacar que as salas multifuncionais são precárias em relação ao que é definido nas diretrizes federais e sua implementação local geralmente não atende às necessidades sociais e às demandas mínimas. Os desafios ao incluir as deficiências também retratam que os professores são negligenciados pela sobrecarga de trabalho e pelo elevado número de estudantes para o AEE.

Parece necessário discutir que, com a TA, surgem alternativas para o trabalho com as diferenças, favorecendo práticas pedagógicas mais dialógicas e interculturais. As contribuições dos recursos da TA ampliam a comunicação no processo de ensino e de aprendizagem com um maior envolvimento de todos, com vistas ao desenvolvimento das necessidades específicas e à ampliação da linguagem. De acordo com Pletsch (2015), a apropriação de linguagem oral, como o "sim" e o "não", torna-se uma condição de possibilidade para que os sujeitos com deficiência possam fazer escolhas simples, como o que comer e vestir, por exemplo, embora esses conhecimentos não sejam considerados da educação formal. Argumentamos, assim, que a TA é um projeto de humanização em sua integralidade, pois está norteada por uma aprendizagem intersubjetiva, que beneficia a dimensão cognitiva de base social e do reconhecimento cultural, valorizando a alteridade e o exercício da cidadania.

\section{CONSIDERAC̣̃̃ES FINAIS}

Embora não possamos enumerar todos os desdobramentos e as implicações da TA para justificar os direitos humanos, as vivências, as práticas cotidianas e o reconhecimento da liberdade do aprender com as diferenças, torna-se importante a análise para evitar distorções sobre o sentido da TA nas relações sociais contemporâneas, enfocando, especialmente, a necessidade de liberdade e de interação como direitos humanos fundamentais para uma vida digna de todos 
os sujeitos. Os resultados apresentados até aqui revelam a validade da TA em termos de servir às necessidades das pessoas e ao apoio educativo inerente às estruturas comunicativo-performativas. Até então, as práticas de segregação social das pessoas com deficiência (sinônimo de doença, incapacidade, dependência, desvalorização humana) estiveram articuladas a fatores da natureza, próprios de cada sujeito, e não foram pensadas como intrinsecamente relacionadas a questões da cultura técnica, humana e política. Considerando a hipercomputação, a biotecnologia e as novas relações que estabelecemos com as tecnologias, também outras ações precisam ser configuradas no campo pedagógico, de modo que a igualdade seja fruto da organização humana, como lembrou Arendt (2012), e que o direito a relacionar-se seja imanente à própria condição humana.

De acordo com Fernandes (2002), o que produz a humanização e determina a desumanização do ser humano não é a distinção físico-mental ou sensorial, mas as visões limitadoras da segregação social, historicamente perpetuadas, em forma de estereótipos excludentes. Trabalhar com as pessoas (respeitando suas deficiências e limitações) a partir da TA como elemento complementar das práticas sociais aparece como uma nova possibilidade de abertura formativa (linguagem/mundo) e intersubjetiva à diversidade da existência. Certamente, as práticas pedagógicas são afetadas por essa compreensão, conduzindo a uma mudança em sua própria natureza - marcada pela instrumentalidade. A concepção e a organização das salas de recursos multifuncionais, as quais integram o AEE, seriam modificadas com vistas a serem espaços fluídos e receptivos à diversidade e à reconstrução de TA, tanto quanto também são múltiplas às necessidades e às potencialidades de cada sujeito. É preciso considerar que a questão da TA na escola cria condições para o estabelecimento de novos padrões sociais de interação, possibilitando aos sujeitos com deficiências se desenvolverem e exercitarem sua condição humana no convívio com o outro, através de processos de sensibilização, inclusão, reconhecimento e cidadania.

Por essas razões, é imprescindível a oferta de uma rede de apoio com diferentes profissionais, criando-se uma cultura que incorpora a deficiência e a diferença como manifestações da condição humana, que merecem ser compreendidas na experiência do reconhecimento mútuo. No palco dos conflitos sociais, as deficiências, muitas vezes, representam e determinam a maneira como criamos e fazemos uso dos artefatos técnicos.

O uso da TA por si só não garante novas formas de aprender com as diferenças e pode gerar a valorização apenas da repetição 
pedagogizadora, que, afastada da realidade, limita a sensibilidade e a linguagem. É preciso que professores e estudantes experimentem as interlocuções com as tecnologias em seu cotidiano de estudo e percebam o seu efeito no desenvolvimento humano e na apropriação dos conhecimentos, olhando a aprendizagem como uma transformação na experiência com a alteridade. Esse é, pois, o grande desafio do trabalho pedagógico com a TA. Precisamos recuperar o sentido das tecnologias para a humanidade, que é ajudar a melhorar as condições de vida de todos, pois somente uma nova sensibilidade, que valoriza a multiplicidade de experiências, pode acolher as reconfigurações das condições políticas do humano no mundo, dando conta da complexidade de tensões e desafios da formação e dos processos de inclusão. Nesses termos, reduzir as tecnologias a uma função autônoma, não social ou simples estratégia compensatória da lógica produtivista contribui também para consolidar alguns mitos sobre a TA, causando desinteresse, apatia e bloqueio educativo para atender às demandas sociais e inclusivas.

\section{REFERÊNCIAS}

ADORNO, T. W. Educação após Auschwitz. In: ADORNO, T. W. Educação e emancipação. Tradução de Wolfgang Leo Maar. Rio de Janeiro: Paz e Terra, 1995. p. 119-138.

ARENDT, H. Origens do totalitarismo: antissemitismo, imperialismo, totalitarismo. Tradução de Roberto Raposo. São Paulo: Companhia das Letras, 2012.

BERSCH, R. Introdução à Tecnologia Assistiva. Porto Alegre: CEDI - Centro Especializado em Desenvolvimento Infantil, 2008.

BERSCH, R.; TONOLLI, J. C. Introdução ao conceito de Tecnologia Assistiva e modelos de abordagem da deficiência. Porto Alegre: CEDI - Centro Especializado em Desenvolvimento Infantil, 2006. Disponível em: <http://www.bengalalegal.com/ tecnologia-assistiva >. Acesso em: 2 fev. 2016.

BEZERRA, A. A. C.; SOUZA, M. A. A. Somos todos seres muito especiais: uma análise psicopedagógica da política de educação inclusiva. Fortaleza, CE: UFC, 2012.

BRASIL. Secretaria Especial dos Direitos Humanos. Subsecretaria Nacional de Promoção dos Direitos da Pessoa com Deficiência. Comitê de Ajudas Técnicas. Tecnologia Assistiva. Brasília: CORDE, 2009a. Disponível em: <http://www.pessoacomdeficiencia.gov.br/app/ sites/default/files/publicacoes/livro-tecnologia-assistiva.pdf>. Acesso em: 31 out. 2016.

BRASIL. Ministério da Educação - MEC. Conselho Nacional de Educação - CNE. Câmara de Educação Básica - CEB. Resolução CNE/CEB n n 4, de 2 de outubro de 2009. Institui Diretrizes Operacionais para o Atendimento Educacional Especializado na Educação Básica, modalidade Educação Especial. Brasília: MEC/CNE/CEB, 2009b. Disponível em: <http://portal.mec.gov.br/dmdocuments/rceb004_09.pdf>. Acesso em: 4 set. 2017.

BRETON, P. A utopia da comunicação. Lisboa: Instituto Piaget, 1994.

CHAUí, M. Uma ideologia perversa. Folha de São Paulo, Caderno Mais!, São Paulo, p. 2, 14 mar. 1999. 
FERNANDES, H. S. Educação especial: integração das crianças e adaptação das estruturas de educação. Braga: APPACDM Distrital, 2002.

FIGUEIREDO, R. V. (Org.). Novas luzes sobre a inclusão escolar. Fortaleza: Ed. da UFC, 2010.

GOFFMAN, E. Estigma: notas sobre a manipulação da identidade deteriorada. Rio de Janeiro: Zahar, 1975.

GOFFREDO, V. L. F. S. A escola como espaço inclusivo. In: BRASIL. Ministério da Educação - MEC. Secretaria de Educação a Distância - SEED. Salto para o futuro: Educação Especial: tendências atuais. Brasília: Ministério da Educação, SEED, 1999. p. 67-72. (Série de Estudos. Educação a Distância, v. 9). Disponível em: <http://www. dominiopublico.gov.br/download/texto/me002692.pdf>. Acesso em: 4 set. 2017.

HABERMAS, J. [1970]. La lógica de las ciências sociales. 3. ed. Madrid: Tecnos, 1996.

HABERMAS, J. A inclusão do outro: estudos de teoria política. Tradução de George Sperber. São Paulo: Loyola, 2004.

HEGEL, G. W. F. Fenomenologia del espiritu. México: Fundo de Cultura Económica, 1987. HEIDEGGER, M. Ensaios e conferências. Tradução de Emmanuel Carneiro Leão. Petrópolis-RJ: Vozes, 2001.

HONNETH, A. Luta por reconhecimento: a gramática moral dos conflitos sociais. Tradução de Luiz Repa. São Paulo: Ed. 34, 2003.

KASSAR, M. C. M. Percursos da constituição de uma política brasileira de Educação Especial inclusiva. Revista Brasileira de Educação Especial, Marília-SP, v. 17, n. Especial 1, p. 41-58, maio/ago. 2011.

LÉVY, P. [1993]. As tecnologias da inteligência: o futuro do pensamento na era da informática. 10. ed. Tradução de Carlos Irineu da Costa. Rio de Janeiro: Ed. 34, 2001.

MASINI, E. F. S. Pesquisas sobre surdocegueira e deficiências sensoriais múltiplas. Revista Construção Psicopedagógica, São Paulo, v. 19, n. 18, p. 64-72, 2011.

NUNES, L. R. D’O. P.; et al. (Org.). Comunicar é preciso: em busca das melhores práticas na educação do aluno com deficiência. São Paulo: ABPEE, 2011.

PERRENOUD, P. A pedagogia na escola das diferenças: fragmentos de uma sociologia do fracasso. Porto Alegre: Artmed Editora, 2001.

PLETSCH, M. D. Deficiência múltipla: formação de professores e processos de ensinoaprendizagem. Revista Cadernos de Pesquisa, São Paulo, v. 45, n. 155, p. 12-29, 2015.

PRESTES, Z. Quando não é quase a mesma coisa: análise de traduções de Lev Semionovitch Vigotski no Brasil - repercussões no campo educacional. 2010. 295 f. Tese (Doutorado em Educação) - Faculdade de Educação, Universidade de Brasília (UnB), Brasília, 2010.

SÁNCHEZ GAMBOA, S. Projetos de pesquisa, fundamentos lógicos: a dialética entre perguntas e respostas. Chapecó: Argos, 2013.

SANTOS, B. de S. Direitos humanos, democracia e desenvolvimento. In: SANTOS, B. de S.; CHAUÍ, M. (Org.). Direitos humanos, democracia e desenvolvimento. São Paulo: Cortez, 2013. p. 41-133.

SHAKESPEARE, T. La autoorganización de las personas con discapacidad: ¿un nuevo movimiento social? In: BARTON, L. (Org.). Superar las barreras de la Discapacidad: 18 años de Disability and Society. Madrid: Morata, 2008. p. 68-85.

WARSCHAUER, M. Tecnologia e inclusão social: a exclusão digital em debate. São Paulo: Editora Senac, 2006. 
WERLE, D. L. Lutas por reconhecimento e justificação da normatividade. 2004. 220 f. Tese (Doutorado em Filosofia) - Faculdade de Filosofia, Letras e Ciências Humanas, Universidade de São Paulo, São Paulo, 2004.

\section{NOTAS}

${ }^{1}$ A questão da deficiência enquanto marginalização opressiva das pessoas diferentes ou em situação de "anormalidade" faz surgir, no fim dos anos de 1970, um movimento de reivindicação dos direitos sociais das pessoas em situação de deficiência, baseado na defesa dos direitos civis e humanos dessas pessoas, destituídas de reconhecimento, coisificadas e impotentes socialmente (SHAKESPEARE, 2008).

${ }^{2} \mathrm{O}$ termo Assistive Technology, traduzido no Brasil como Tecnologia Assistiva, foi criado em 1988 como elemento jurídico dentro da legislação norte-americana conhecida como Public Law 100-407, que compõe o American with Disabilities Act. Na verdade, a TA ganhou uma forte dimensão social a partir do fim da Segunda Guerra Mundial, quando os EUA e os países europeus buscaram alternativas para reabilitar os deficientes, projetando tecnologias de acessibilidade e capacitação humana (BERSCH; TONOLLI, 2006).

${ }^{3}$ A TA é todo o arsenal de recursos, serviços, estratégias e práticas que contribuem para proporcionar ou ampliar habilidades funcionais de pessoas com necessidades especiais, promovendo vida independente e inclusão humana (BERSCH; TONOLLI, 2006).

${ }^{4}$ Ainda hoje, percebe-se que os professores são refratários ao outro, ao diferente com traços de um corpo com necessidades especiais, esquecendo-se de que o corpo que aprende é aquele que se relaciona e interage com o outro no movimento que habita na linguagem (expressão, sentidos, gestos, percepção, emoção) e constitui a totalidade do ser, produzindo metamorfoses no reconhecimento aprendente.

${ }^{5}$ Redação iMasters em Tecnologia, Tendências. Desenvolvimento de tecnologia assistiva gera 1,5 mil produtos no Brasil, de 25 de agosto de 2015. Disponível em: < http://imasters.com. $\mathrm{br} /$ noticia/desenvolvimento-de-tecnologias-assistivas-gera-15-mil-produtos-no-brasil $>$. Acesso em: 31 out. 2016.

${ }^{6} \mathrm{O}$ site do Disability History Museum exibe muitos textos dessa época, inclusive fotos tiradas a partir de 1918. Disponível em: <www.disabilitymuseum.org>. Acesso em: 31 out. 2016.

${ }^{7}$ Santos (2013) aponta para os perigos do enredamento em um discurso triunfalista ou descontextualizado acerca dos direitos humanos, sob pena de estar a serviço das forças totalitárias que visa combater: "O que normalmente não é referido é que, desde então [séc. XVIII] até aos nossos dias, os direitos humanos foram usados, como discurso e como arma política, em contextos muito distintos e com objetivos contraditórios. No século XVIII, por exemplo, os direitos humanos eram parte integrante dos processos revolucionários em curso e foram uma das suas linguagens. Mas também foram usados para legitimar práticas que consideramos opressivas se não mesmo contrarrevolucionárias. Quando Napoleão chegou ao Egito, em 1798, explicou assim as suas ações aos egípcios: 'Povo do Egito. Os nossos inimigos vão dizer-vos que eu vim para destruir a vossa religião. Não acrediteis neles. Dizeilhes que eu vim restaurar os vossos direitos, punir os usurpadores, e erguer a verdadeira devoção de Maomé”' (SANTOS, 2013, p. 47-48).

${ }^{8} \mathrm{~A}$ diferenciação quanto aos termos usados nos documentos oficiais brasileiros advém das adequações dos países de origem dos termos, Assistive Technology, em países de língua inglesa; Ayudas Técnicas, em língua espanhola, e Tecnologia de Apoio na tradução de 
Portugal para Assistive Technology (BRASIL, 2009a). Por Ajudas Técnicas ou produtos assistivos depreendemos os artefatos que complementam e aperfeiçoam a regulamentação de Tecnologia Assistiva no país (escrito no singular TA, por se tratar de uma área do conhecimento), e define-se qualquer produto (incluindo dispositivos, equipamentos, instrumentos, tecnologia e software) fabricado especialmente ou geralmente disponível no mercado, para prevenir, compensar, controlar, atenuar ou neutralizar deficiências, limitações na atividade e restrições na participação.

${ }^{9}$ A lógica do reconhecimento mútuo entre as pessoas é manifestada na obra de Hegel (1987) e passa pela relação social (interdependente, deficitária, patológica, dominadora) e reflexiva que construímos no encontro com o outro.

Submetido: 07/04/2016

Aprovado: 26/07/2017

Contato:

Elaine Conte

Rua São Vicente, 32/302. Bairro Rio Branco.

Porto Alegre|RS|Brasil

CEP 90.630-180 